\title{
EDITORIAL
}

\section{The baby lung and the COVID-19 era}

\author{
Luciano Gattinoni ${ }^{1^{*}} \mathbb{D}$, Konrad Meissner ${ }^{1}$ and John J. Marini ${ }^{2}$
}

(c) 2020 The Author(s)

The concept of the baby lung was born in 1987 [1] when quantitative $\mathrm{CT}$ scan analysis demonstrated that, in severe ARDS, the amount of the ventilatable lung tissue of an adult was similar to that of a 6-year-old healthy child. We called it a "baby lung."

Three features seemed apparent: (1) The baby lung was anatomically located in the non-dependent lung regions (parasternal, when supine), while the radiological densities were primarily located in the dependent regions (paravertebral); (2) the respiratory system compliance was a useful tool with which to estimate the baby lung size [1]. Indeed, compliance was not an inverse function of the amount of non-aerated tissue, but instead correlated strongly with the amount of well-aerated lung. In other words, measured compliance characterizes only those lung units that receive the gas volume. This finding changed a prevailing concept of ARDS important to its management: The lung was not stiff, as commonly believed at that time, but small; (3) the specific compliance (i.e., respiratory system compliance measured in the ventilating circuit normalized to the size of the baby lung) was similar for healthy individuals and ARDS patients. That fact does not necessarily mean that the baby lung is healthy, but does indicate that its mechanical characteristics are preserved, exclusive of the possible presence of fibrosis or deficit of surfactant.

The anatomical location of the baby lung led us to introduce the prone position as a treatment for ARDS [2]. Indeed, we thought that the anatomically situated parasternal baby lung should be better perfused in the prone position, with resulting improvement in oxygenation and possibly a decrease in $\mathrm{PaCO}_{2}$. Actually, an increase in oxygenation was observed in the majority of patients,

\footnotetext{
*Correspondence: gattinoniluciano@gmail.com

${ }^{1}$ Department of Anesthesiology, Intensive Care and Emergency Medicine, Medical University of Göttingen, Göttingen, DE, Germany Full author information is available at the end of the article
}

with $\mathrm{PaO}_{2}$ increasing even more than $100 \mathrm{mmHg}$ for the same $\mathrm{FiO}_{2}$. However, almost one year later, we also took a CT scan in the prone position, and to our surprise, we found that the anatomically envisioned baby lung disappeared in the parasternal regions, while a new baby lung appeared in the dorsal zone [3]. This finding convincingly negated the concept of the anatomical baby lung and replaced it with the concept of the functional baby lung. Understanding the mechanism behind this positional switch implied the need to perform and compare regional analyses of $\mathrm{CT}$ in both supine and prone positions. Doing so led to the model of the "sponge lung" [4]. Indeed, the densities in the dependent lung regions, whether in supine or prone positions, were primarily due to superimposed hydrostatic pressures that compress the lung along the vertical gravitational axis. More importantly, it appeared evident that the densities were not due to the movement of edema but instead due to squeezing gas from the alveoli by compressive forces. This led also to a revised hypothesis for the mechanism of PEEP's benefit, which now would act as a counterforce against superimposed pressure, thereby preventing the expulsion of alveolar gas and atelectasis.

This model, actually without significant changes, held reasonably true until the COVID-19 era [5]. Several COVID patients at hospital presentation met the broad ARDS definition criteria. Indeed, the hypoxemia qualifies, on the basis of $\mathrm{PaO}_{2} / \mathrm{FiO}_{2}$, and bilateral infiltrates on chest X-ray are present. However, even though many authors continue to characterize this presentation as "ARDS" (which is a syndrome) and proceed accordingly, it must be recognized that, in many cases, we deal with an atypical ARDS [6]. Indeed, at the beginning this atypical syndrome does not show a baby lung, but as measured by the quantitative CT scan an "adult lung," with normal mechanics and normal specific compliance [7]. It would be interesting to know, however, if and how the adult lung of early or mild COVID-19 pneumonia transitions to a baby lung. Is this due only to disease progression or

\section{Springer}




\section{DEVELOPMENT OF THE BABYLUNG CONCEPT}

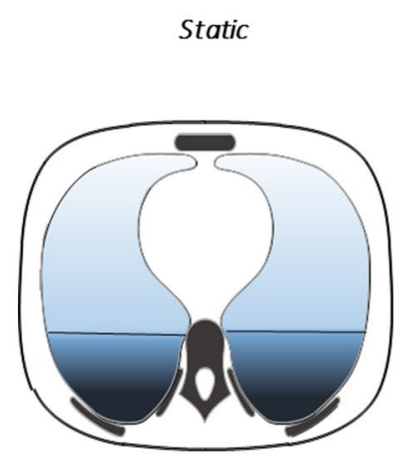

Anatomical babylung

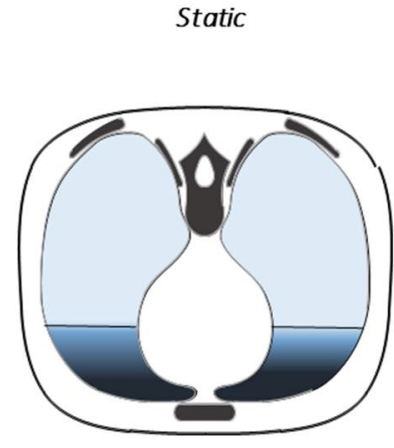

Functional babylung

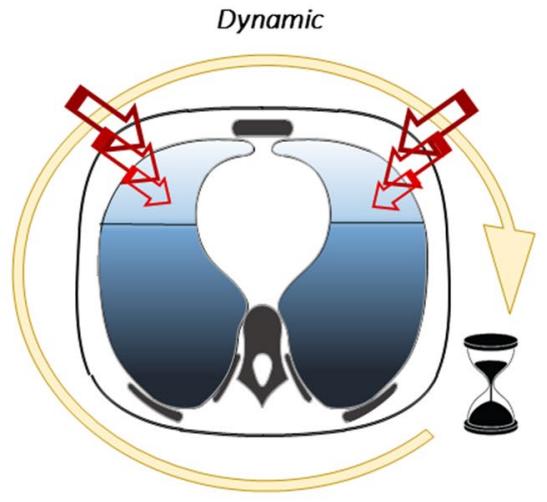

Shrinking babylung

Fig. 1 Evolving concept of the "baby lung" of ARDS. Initial interpretation of the supine CT images suggested a fixed anatomical location (left panel). Subsequently, the shifting of the aerated compartment by prone repositioning demonstrated its lack of structurally fixed location, functional nature, and responsiveness to changes in transpulmonary pressure (middle panel). The vulnerability of aerated lung units to progressively concentrating power that injures and promotes dropout of lung units from the functional compartment over time is implicit in the current "dynamic" model of the shrinking baby lung (right panel)

also to inappropriate treatment which, in the absence of interventions, forces the adult lung to shrink progressively and deteriorate through a sort of "VILI vortex" [8] of concentrating injurious mechanical power [9]?

After becoming infected, only a minority of COVID patients develop bilateral pneumonia and hypoxemia [10]. The radiological lesions present initially as "ground glass" infiltrates located primarily near the visceral pleura. This location is similar to the one we found in experimental animals when VILI is produced with high tidal volume [11]. In these patients, the hypoxemia is primarily due to the VA/Q maldistribution caused by the loss of the lung perfusion regulation. Respiratory drive is highly activated because of hypoxemia, infection, and possibly direct presence of virus in the central nervous system. High tidal volume follows (increased strain) in association with higher transpulmonary pressure (stress). If this increase in stress and strain remains without correction, patient self-inflicted lung injury develops, causing overt lung edema [12]. Dependent regions of the lung then tend to collapse due to the increased hydrostatic superimposed pressure [13], and the lung transitions from the adult size to the baby lung size, with a parallel decrease in respiratory system compliance. If the conditions leading to increased stress and strain remain unchecked, the VILI vortex develops. Indeed, for any increase in edema and reduction in the lung size, stress and strain are more concentrated in a smaller lung and promote a vicious cycle. It is therefore mandatory to interrupt this sequence of events which cause the baby lung to shrink and become more vulnerable. For many authors, the concept of VILI does not include the vascular side of the alveolus which is, in our opinion, of similar importance as the gas side, particularly in COVID. Indeed, the forces of mechanical power (a function of strain, stress, and respiratory rate) are primarily applied to the extracellular matrix to which both the epithelial and endothelial cells are anchored. The strain of these two cell populations contributes through a cytokine release to a further recruitment of inflammatory cells. Although the lung mechanics of the baby lung are not dramatically changed, the reaction to and tolerance of repeated cycles of high stress and strain is profoundly altered by the inflammatory reaction. This effect has been shown in CT-PET studies in which the inflammation was often recognized in the well-aerated tissue compartment [14].

It is beyond the purpose of this paper to discuss the therapy of COVID-19. At its core, however, is the prevention/interruption/reduction of the VILI vortex, keeping well in mind that PEEP modifies both stress and strain and contributes to the applied mechanical power [15].

In summary (Fig. 1), the baby lung concept evolved from a static representation ("anatomic entity located in the non-dependent lung") to a static functional model ("sponge lung") to dynamic entity subject over time to the VILI vortex if not maintained and preserved. 


\section{Author details}

${ }^{1}$ Department of Anesthesiology, Intensive Care and Emergency Medicine, Medical University of Göttingen, Göttingen, DE, Germany. ${ }^{2}$ Regions Hospital, St. Paul, MN, USA.

\section{Acknowledgements}

Open Access funding provided by Projekt DEAL.

\section{Compliance with ethical standards}

\section{Conflicts of interest}

The authors declare that they have no conflict of interest.

\section{Open Access}

This article is licensed under a Creative Commons Attribution-NonCommercial 4.0 International License, which permits any non-commercial use, sharing, adaptation, distribution and reproduction in any medium or format, as long as you give appropriate credit to the original author(s) and the source, provide a link to the Creative Commons licence, and indicate if changes were made. The images or other third party material in this article are included in the article's Creative Commons licence, unless indicated otherwise in a credit line to the material. If material is not included in the article's Creative Commons licence and your intended use is not permitted by statutory regulation or exceeds the permitted use, you will need to obtain permission directly from the copyright holder. To view a copy of this licence, visit http://creativecommons.org/licen ses/by-nc/4.0/.

\section{Publisher's Note}

Springer Nature remains neutral with regard to jurisdictional claims in published maps and institutional affiliations.

Received: 4 May 2020 Accepted: 9 May 2020

Published online: 25 May 2020

\section{References}

1. Gattinoni L, Pesenti A, Avalli L, Rossi F, Bombino M (1987) Pressure-volume curve of total respiratory system in acute respiratory failure. Computed tomographic scan study. Am Rev Respir Dis 136(3):730-736

2. Langer M, Mascheroni D, Marcolin R, Gattinoni L (1988) The prone position in ARDS patients. A clinical study. Chest 94(1):103-107

3. Gattinoni L, Pelosi P, Vitale G, Pesenti A, D'Andrea L, Mascheroni D (1991) Body position changes redistribute lung computed-tomographic density in patients with acute respiratory failure. Anesthesiology 74:15-23
4. Bone RC (1993) The ARDS lung. New insights from computed tomography. JAMA 269:2134-2135

5. Arabi YM, Murthy S, Webb S (2020) COVID-19: a novel coronavirus and a novel challenge for critical care. Intensive Care Med 46(5):833-836

6. Gattinoni L, Coppola S, Cressoni M, Busana M, Rossi S, Chiumello D (2020) Covid-19 does not lead to a "typical" acute respiratory distress syndrome. Am J Respir Crit Care Med 201(10):1299-1300

7. Gattinoni L, Chiumello D, Caironi P, Busana M, Romitti F, Brazzi L, Camporota L (2020) COVID-19 pneumonia: different respiratory treatment for different phenotypes. Intensive Care Med. https://doi.org/10.1007/s0013 4-020-06033-2

8. Marini JJ, Gattinoni L (2020) Time course of evolving ventilator-induced lung injury: the "Shrinking Baby Lung". Crit Care Med. https://doi. org/10.1097/CCM.00000000000004416

9. Gattinoni L, Tonetti T, Cressoni M, Cadringher P, Herrmann P, Moerer O, Protti A, Gotti M, Chiurazzi C, Carlesso E, Chiumello D, Quintel M (2016) Ventilator-related causes of lung injury: the mechanical power. Intensive Care Med 42:1567-1575

10. Zhou F, Yu T, Du R, Fan G, Liu Y, Liu Z, Xiang J, Wang Y, Song B, Gu X, Guan L, Wei Y, Li H, Wu X, Xu J, Tu S, Zhang Y, Chen H, Cao B (2020) Clinical course and risk factors for mortality of adult inpatients with COVID-19 in Wuhan, China: a retrospective cohort study. Lancet 395:1054-1062

11. Cressoni M, Chiurazzi C, Gotti M, Amini M, Brioni M, Algieri I, Cammaroto A, Rovati C, Massari D, di Castiglione CB, Nikolla K, Montaruli C, Lazzerini M, Dondossola D, Colombo A, Gatti S, Valerio V, Gagliano N, Carlesso E, Gattinoni L (2015) Lung inhomogeneities and time course of ventilatorinduced mechanical injuries. Anesthesiology 123:618-627

12. Brochard L (2017) Ventilation-induced lung injury exists in spontaneously breathing patients with acute respiratory failure: yes. Intensive Care Med 43:250-252

13. Pelosi P, D'Andrea L, Vitale G, Pesenti A, Gattinoni L (1994) Vertical gradient of regional lung inflation in adult respiratory distress syndrome. Am J Respir Crit Care Med 149:8-13

14. Cressoni M, Chiumello D, Chiurazzi C, Brioni M, Algieri I, Gotti M, Nikolla K, Massari D, Cammaroto A, Colombo A, Cadringher P, Carlesso E, Benti R, Casati R, Zito F, Gattinoni L (2016) Lung inhomogeneities, inflation and [18F]2-fluoro-2-deoxy-D-glucose uptake rate in acute respiratory distress syndrome. Eur Respir J 47:233-242

15. Serpa Neto A, Deliberato RO, Johnson AEW, Bos LD, Amorim P, Pereira SM, Cazati DC, Cordioli RL, Correa TD, Pollard TJ, Schettino GPP, Timenetsky KT, Celi LA, Pelosi P, Gama de Abreu M, Schultz MJ, Investigators PN (2018) Mechanical power of ventilation is associated with mortality in critically ill patients: an analysis of patients in two observational cohorts. Intensive Care Med 44:1914-1922 